\title{
Sistema COMPLEMENTO: ATIVAÇÃO, REGULAÇÃO E DEFIIIENCIAS CONGÊNITAS E ADQUIRIDAS
}

\author{
*G.R. Iturry-Yamamoto, C.P. Portinho \\ UnidadedeHemodinâmica-Senviço deCardiologiadoHospital deClínicas dePortoAlegre, Departamento deFarmacologia- \\ FaculdadedeMedicina-UniversidadeFederal do RioGrandedoSul, PortoAlegre, RS.
}

Unitermos: Sistema complemento.Ativação. Regulação. Deficiências. Imunidade humoral. Sistema imune.

Kerwords: Complement system. Activation. Regulation. Deficiencies. Humoral immunity. Immune system.

\section{INTRODUÇÃO}

O sistema complemento (SC) é o principal mediador humoral do processo inflamatório junto aos anticorpos. Está constituído por um conjunto de proteínas, tanto solúveis no plasma como expressas na membrana celular, e é ativado por diversos mecanismos por duas vias, a clássica e a alternativa.

A incidência das imunodeficiências primárias ou genéticas é de cerca de I : 10.000 crianças, excluindo-se a deficiência seletiva assintomática de IgA. O SC compreende apenas 2\% destas, como demonstra a figura I. A deficiência de uma ou mais proteínas da cascata do SC, contudo, poderá ser responsável pela suscetibilidade aumentada a várias doenças. As deficiências podem ser genéticas, quando poderão faltar componentes de ativação, de regulação ou mesmo de receptores ou adquiridas ${ }^{2}$.

As deficiências de proteínas do SC são incomuns, mas não raras. Por exemplo, a freqüência da deficiência heterozigótica de C2 é de cerca de 1:100 nascidos vivos, enquanto que da homozigótica é de cerca

*Correspondência:

R. RamiroBarcelos, 2.350-sala 2061

Cep: 90035-003-PortoAlegre-RS

\section{Figura I - Distribuição relativa das imunodeficiências primárias. A deficiência primária mais comum dentro do sistema complemento é a de $C 2$.}

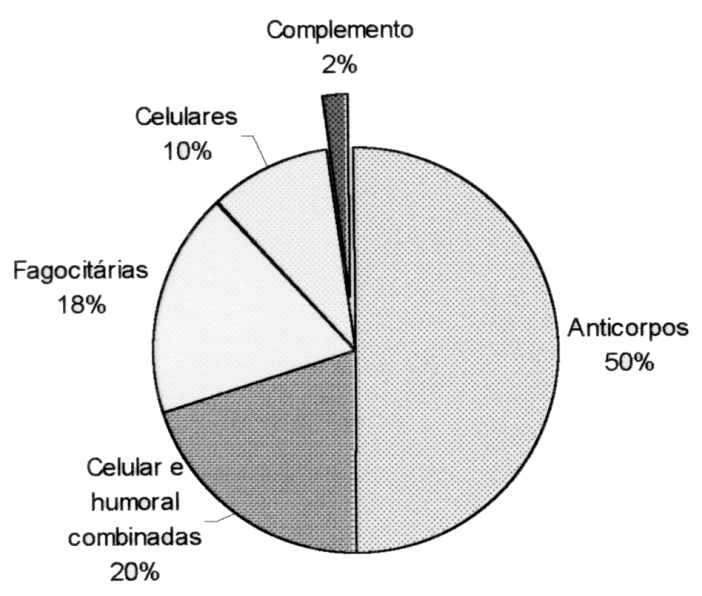

de 1:10.000. A deficiência dos componentes iniciais da via clássica pode estar associada com saúde normal, doenças do colágenos ou infecções. As deficiências de C3 ou de proteínas reguladoras de C3 freqüentemente levam a infecções severas. As deficiências de componentes da via alternativa ou da via efetora comum podem acarretar infecções, particularmente por Neisseria spp. A deficiência de inibidor de $\mathrm{Cl}$ causa angioedema².

\section{Evolução do SC}

Designa-se SC a um complexo protéico polimolecular constituído por várias substâncias que se encontram no plasma sangüíneo, nas membranas celulares e desempenham um papel importante em diferentes tipos de reações imunoinflamatórias ${ }^{3}$. A tabela I mostra algumas propriedades dos componentes plasmáticos do SC.

Nos mamíferos, o SC tem um papel importante nos mecanismos de defesa inatos e adquiridos. Trata-se de um sistema antigo de defesa, já presente nos deuterostomos invertebrados. Nessa espécie, assim como nos agnathans (as espécies vertebradas mais primitivas), a via alternativa está 
Tabela I - Componentes plasmáticos da cascata do sistema complemento.

\begin{tabular}{|c|c|c|c|c|c|}
\hline Componente & $\begin{array}{r}\text { PM } \\
(k d)\end{array}$ & $\begin{array}{l}\text { Concentração } \\
\text { sérica }(\mu \mathrm{g} / \mathrm{ml})\end{array}$ & TL & $\begin{array}{l}\text { Produtos } \\
\text { da ativação }\end{array}$ & Comentários sobre as funções \\
\hline $\begin{array}{l}\text { Via clássica } \\
\text { Cl }\end{array}$ & 900 & & & & Inicia ativação da via clássica. \\
\hline $\mathrm{Clq}$ & 410 & 75 & + & & Liga-se a porção Fc da lg. \\
\hline Clr & 85 & 50 & + & $\mathrm{Clr}$ & Protease sérica, cliva Cls. \\
\hline $\mathrm{Cls}$ & 85 & 50 & + & $\mathrm{Cls}$ & Protease sérica, cliva C4 e C2. \\
\hline C4 & 210 & $200-500$ & - & $\mathrm{C} 4 \mathrm{a} C 4 \mathrm{~b}$ & $\begin{array}{l}\text { C4a é uma anafilatoxina. C4b } \\
\text { forma ligações covalentes com } \\
\text { as superfícies ativadoras, onde } \\
\text { faz parte da C3 convertase. }\end{array}$ \\
\hline C2 & 110 & 20 & + & $\mathrm{C} 2 \mathrm{a} C 2 \mathrm{~b}$ & $\begin{array}{l}\text { Protease sérica, faz parte da } \\
\text { C3 e C5 convertases }\end{array}$ \\
\hline $\begin{array}{l}\text { Via Alternativa } \\
\text { Fator B }\end{array}$ & 93 & 200 & + & $\mathrm{BaBb}$ & $\begin{array}{l}\text { Bb é uma protease que faz } \\
\text { parte de } \mathrm{C} 3 \text { e } \mathrm{C} 5 \text { convertases. }\end{array}$ \\
\hline Fator D & 25 & $1-2$ & + & D & $\begin{array}{l}\text { Protease que circula na forma } \\
\text { ativa, cliva o fator } B \text {. }\end{array}$ \\
\hline $\begin{array}{l}\text { C3 (pertence à via } \\
\text { clássica também) }\end{array}$ & 195 & $550-1200$ & - & $\mathrm{C} 3 \mathrm{a} C 3 \mathrm{~b}$ & $\begin{array}{l}\text { C3a é uma anaflaxina. C3b forma } \\
\text { ligações covalentes com a } \\
\text { superfície ativadora, onde é parte } \\
\text { da C3 e C5 convertases; } \\
\text { atua também como opsonina. }\end{array}$ \\
\hline Properdina & 220 & 25 & & & $\begin{array}{l}\text { Estabiliza a C3 convertase da } \\
\text { via alternativa. }\end{array}$ \\
\hline $\begin{array}{l}\text { Via efetora comum } \\
\text { C5 }\end{array}$ & 190 & 70 & + & $\mathrm{C} 5 \mathrm{a}$ C5b & $\begin{array}{l}\text { C5a é uma anafilaxina. C5b } \\
\text { inicia a formação do CLM. }\end{array}$ \\
\hline C6 & 128 & 60 & & & Componente do CLM. \\
\hline $\mathrm{C7}$ & $|2|$ & 60 & & & Componente do CLM. \\
\hline C8 & 155 & 60 & + & & Componente do CLM. \\
\hline C9 & 79 & 60 & + & & $\begin{array}{l}\text { Componente do CLM, sofre } \\
\text { polimerização para formá-lo. }\end{array}$ \\
\hline
\end{tabular}

$\mathrm{PM}=$ peso molecular. $\mathrm{Kd}=$ =Kilodalton. $\mathrm{TL}=$ termolabilidade. $\mathrm{CLM}=$ Complexo Lítico de Membrana. Ig=Imunoglobina.

presente, e o SC parece estar envolvido principalmente na opsonização de material estranho. Com a emergência das imunoglobulinas no peixe cartilaginoso, aparecem também as vias clássica e lítica. O resto das espécies pecilotérmicas, desde os teleostos aos répteis, parece ter um SC bem desenvolvido, lembrando aquele dos vertebrados homeotérmicos. Contudo, há diferenças importantes que permanecem. Ao contrário dos homeotérmicos, diversas espécies de pecilotérmicos atualmente possuem múltiplas formas de componentes do SC (C3 e fator B), que são estrutural e funcionalmente mais diversificados do que nos vertebrados mais evoluídos. É notório que as formas múltiplas de C3 que foram caracterizadas em vários peixes teleostos são capazes de ligar-se a várias superfícies que ativam o SC4.

Representação dos Componentes do SC

Os componentes da via clássica, assim como da via terminal, são designados com o símbolo " $\mathrm{C}$ " seguidos com o número correspondente $(\mathrm{Cl}, \mathrm{C} 3$, etc.). Já os componentes da via alternativa, exceto $\mathrm{C} 3$, são designados com nomes convencionais ou símbolos diferentes (exemplo: fator D, fator B, properdina). A designação dos componentes ativados é feita por uma barra colocada sobre o símbolo da proteína ou do complexo protéico correspondente (exemplo: $\overline{C l}-C 4 b 2 a$, fator $\bar{B}$, etc.). Os produtos 
da clivagem enzimática são designados por letras minúsculas que seguem o símbolo de determinado componente (exemplo: C5a, C5b). Quando o componente ou fragmento é inativado, é adicionada a letra "i" (exemplo: C3bi, Bbi).

As proteínas do SC são sintetizadas principalmente nos hepatócitos e macrófagos/ monócitos $^{6,7}$, além de outros tecidos ${ }^{8}$. As proteínas reguladoras ligadas à membrana celular são sintetizadas nas células sobre as quais estão expressas?.

O SC constitui-se num dos principais efetores da imunidade humoral assim como da inflamação ${ }^{10,11}$. O SC participa dos seguintes processos biológicos: fagocitose, opsonização, quimiotaxia de leucócitos, liberação de histamina dos mastócitos e basófilos e de espécies ativas de oxigênio pelos leucócitos, vasoconstrição, contração da musculatura lisa, aumento da permeabilidade dos vasos, agregação plaquetária e citólise $^{11-18}$.

\section{Ativação do SC}

Para que o SC exerça as suas funções, deve ser ativado, originando assim uma série de fragmentos com diferentes características e funções especificas. Esta ativação ocorre por duas vias: a clássica e a alternativa. Cada uma delas é desencadeada por fatores diferentes, sendo o início da ativação diferente para cada uma, mas que convergem em uma via comum a partir da formação de $\mathrm{C} 3 b^{11,19}$.

Sua ativação tanto pela via clássica como pela via alternativa leva à formação do complexo lítico de membrana (CLM), que destrói células. A opsonização leva ao reconhecimento das moléculas do SC pelos receptores para complemento nos fagócitos e pelas imunoglobulinas ${ }^{18}$. A figura 2 mostra as duas vias de ativação da cascata do SC.

A ativação da via clássica do SC é iniciada pela ligação de $\mathrm{Cl}$ q à porção $\mathrm{Fc}$ (fragment crystalline) de uma imunoglobulina. A via
Figura 2 - Cascata do sistema complemento. As vias clássica e alternativa terminam na via efetora comum, que gera o complexo lítico de membrana.

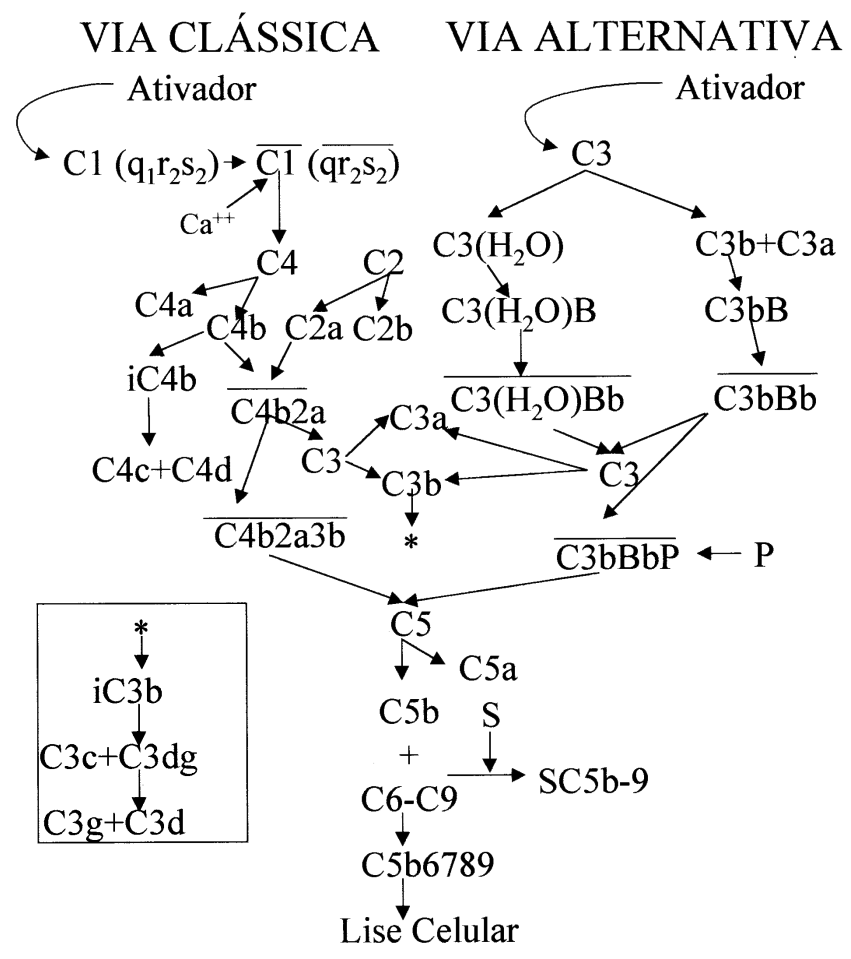

alternativa é ativada continuamente na fase fluída em pouca intensidade; na presença de um ativador exógeno, esta é amplificada. Isso inicia uma cascata de eventos proteolíticos, resultando na formação de C5 convertase da via clássica e alternativa, que cliva a molécula de $\mathrm{C} 5$ em C5b e C5a. O C5b liga-se, por sua vez, a C6, C7 e C8 para formar o complexo C5b-8. A ligação de C9 forma o C5b-9 ou CLM. Esse complexo liga-se à membrana das células-alvo e provoca a formação de "poros", que permitem um influxo descontrolado de água e íons, com turgência e lise celular subseqüentes. Para controlar a atividade do SC, há inibidores endógenos regulados pela própria citólise. Essa regulação protege as células autólogas do ataque do $\mathrm{SC}^{20}$.

O Controle da Ativação e Fuga do Ataque Imune por Microrganismos: a Subversão Imune.

Alguns microrganismos desenvolveram meios de evitar a opsonização e a ação lítica do $\mathrm{SC}^{18}$. Este mecanismo é conhecido como subversão imune. $O$ bacilo da tuberculose é capaz de cobrir-se com a proteína C3 e invade os macrófagos através da interação com receptores do SC ${ }^{2 !}$. Os vírus também possuem essa capacidade de fugir ao ataque imune mediado por anticorpos e SC. O herpesvírus e o coronavírus codificam proteínas ligantes às porções $\mathrm{Fc}$ de $\lg \mathrm{G}$, que inibem a atividade dessas imunoglobulinas. O herpesvírus, assim como o vaccinia vírus e o vírus da imunodeficiência humana (HIV) tipo I têm a capacidade de interferir no SC, tanto por incorporação nos seus envelopes de proteínas reguladoras do complemento, como por expressão de moléculas virais que mimetizam a função dessas proteínas reguladoras. $O$ vírus do HIV tem, ainda, uma proteinase que cliva o componente $\mathrm{C}^{22}$. O vírus do herpes simples tipo I (HSV-I) tem glicoproteínas gE, gl 
e gC, que o protegem do ataque imune; $\mathrm{gE} /$ gl formam um complexo que se liga ao domínio $\mathrm{Fc}$ de uma lgG, enquanto que gC liga-se à proteína regulatória de $\mathrm{C}^{2} \mathrm{~b}^{23}$.

A molécula CD46, regulador do SC, é também um receptor para o vírus do sarampo. A distribuição ampla desse receptor contribui para a infecção por sarampo, mas também para uma proteção autóloga contra o ataque do SC $^{24}$.

\section{Via Clássica de Ativação do SC}

Essa via foi assim denominada por ser a primeira a ser descrita ${ }^{19}$. Formam parte dela os componentes $\mathrm{Cl}, \mathrm{C4}, \mathrm{C} 2$ e C3 ativados em cascata.

\section{Componente $\mathbf{C l}$}

Um complexo molecular multimérico com p.m. de 900 kD, composto de uma subunidade $\mathrm{Cl}$ q, associada a duas moléculas $\mathrm{Cl}$ r e duas moléculas $\mathrm{Cl}$ s por ligações dependentes de cálcio ${ }^{25}$. Clq é a subunidade que se liga à molécula de imunoglobulina. Cl r e Cls são esterases necessárias para a progressão da ativação da cascata ${ }^{26}$.

\section{Componente $\mathbf{C 4}$}

A segunda proteína sérica a ser ativada nesta via. É uma betaglobulina composta por três cadeias polipeptídicas denominadas alfa, beta e gama, com p.m. de 210 kD. A molécula de C4 contém uma ligação tioéster na cadeia alfa. A clivagem de C4 por $\mathrm{Cls}$ forma C4a e C4b. Como resultado desta clivagem, a ligação tioéster da cadeia alfa converte-se em uma ligação instável, suscetível ao ataque de grupos nucleofilicos ${ }^{26}$.

\section{Componente $\mathbf{C 2}$}

Consiste de uma cadeia polipeptídica com p.m. de 110 kD. A clivagem desta molécula forma $\mathrm{C} 2 \mathrm{a}$ e $\mathrm{C} 2 \mathrm{~b}^{26}$. O componente C3 será descrito posteriormente.

\section{Ativação da Via Clássica do SC}

A via clássica é ativada principalmente por complexos antígeno-anticorpo e imunoglobulinas agregadas ${ }^{10}$. As imunoglobulinas humanas que iniciam a ativação do complemento pela via clássica pertencem às classes $\lg M$ e às subclasses $\lg G 1, \lg G 2$, $\lg 3^{9}, 10$. A ativação da via clássica se inicia com a ativação de $\mathrm{Cl}$.

A reação entre o antígeno e o anticorpo forma um imunocomplexo criando um sítio na porção Fc da imunoglobulina acessível à ligação com $\mathrm{Cl}$ q, iniciando-se assim a ativação de $\mathrm{Cl}^{27}$. Após a geração seqüencial de diferentes sítios enzimáticos em Clr, é exposto um novo sítio enzimático em $\mathrm{Cls}$ transformando-se em uma enzima proteolítica, a Cl-esterase ${ }^{28}$. Os íons $\mathrm{Ca}^{++}$são essenciais a fim de prevenir a dissociação de $\mathrm{Cl}$-esterase de $\mathrm{Clq}$, o qual permanece ligado à membrana alvo através das imunoglobulinas $\left.{ }^{2}\right)$. A Cl-esterase cliva dois outros componentes do complemento: $\mathrm{C} 4$ e C2, formando $\mathrm{C} 4 \mathrm{~b}$ que adere-se à membrana celular através de sua ligação tioéster, e C2a que permanece ligado a C4b na presença de íons $\mathrm{Mg}^{30}$, formando assim C4b2a, chamada também de C3-convertase da via clássica $^{31}$, a qual por sua vez cliva C3 em C3a e C3b. Seqüencialmente, C3b se liga a C3convertase, formando C4b2a3b; este novo complexo molecular pode agora clivar $\mathrm{C} 5$, sendo por isso chamado de $\mathrm{C} 5$-convertase da via clássica, formando-se C5a e C5b. C5b inicia a formação do CLM ${ }^{32}$, descrito posteriormente.

Moléculas de C3b formadas através da via clássica podem servir de substrato para a ativação da via alternativa. Este mecanismo é chamado de alça de amplificação?.

\section{Via Alternativa de Ativação do SC}

Em 1954, Pillemer demonstrou que o complemento podia ser ativado por outros agentes, além do complexo antígeno-anticorpo ${ }^{33}$, pela evidência de que a incubação de soro não imune com polissacarídeos como o zimosan podia levar ao consumo do complemento.

Uma proteína sérica, denominada properdina, parecia estar envolvida neste processo. Atualmente sabe-se que a principal função desta é estabilizar a convertase de $\mathrm{C} 3$ e C5,34.

A ativação da via alternativa depende dos seguintes fatores: fator $D$, fator $B$, properdina e C3. O fator $\mathrm{B}$ (pré-ativador de C3) é uma betaglobulina termolábil, com p.m. de 93 kD, que consiste de uma única cadeia polipeptídica ${ }^{35}$. O fator $D$ é uma alfaglobulina termo lábil, de p.m. de 25 kD, que consiste de uma cadeia polipeptídica única ${ }^{35}$, uma enzima que existe no organismo na forma ativada ${ }^{34}$, e que cliva o fator $B$, formando $\mathrm{Bb}$. A properdina, uma gamaglobulina tetramérica com p.m. de 220 $\mathrm{kD}^{30}$, é uma das proteínas reguladoras da via alternativa do complemento, sendo sua principal função estabilizar a convertase de C3 e C5?.

A molécula de C3 cumpre um papel importante no SC, já que faz parte de ambas as vias de ativação da cascata. É uma betaglobulina com p.m. de 195 kD. A molécula de C3 contém uma ligação tioéster interna inerte, a qual pode ser hidrolisada pela água, iniciando assim a ativação da via alternativa. Após a hidrólise, forma-se um grupo sulfidrila e outro éster?.

\section{Ativação da Via Alternativa do SC}

A presença de certos agentes como determinados fungos e bactérias, alguns tipos de vírus e helmintos com determinadas características, especialmente a ausência de ácido siálico na membrana, são suficientes para ativar a via alternativa, através da ligação de uma ou mais moléculas de C3b na sua superfície $e^{28,36}$. A membrana da hemácia de coelho possui também esta propriedade ${ }^{37}$.

A via alternativa pode também ser ativada por lipopolissacarídeos presentes em membranas de várias bactérias, proteínas da 
superfície viral e de parasitas, enzimas tipo tripsina, alguns imunocomplexos e o fator de veneno de cobra ${ }^{19,38}$. Há evidências de que alguns constituintes subcelulares do músculo cardíaco podem ativar a via alternativa ${ }^{39}$.

C3 é também ativado continuamente em pouca intensidade na fase fluída. Isto ocorre através de proteases séricas, moléculas nucleofilicas ou água que atacam a ligação tioéster. Quando esta ligação é hidrolisada, forma-se $\mathrm{C} 3\left(\mathrm{H}_{2} \mathrm{O}\right)^{9}$. A molécula de $\mathrm{C} 3\left(\mathrm{H}_{2} \mathrm{O}\right)$ formada, com uma conformação similar a C3b, na presença de íons $\mathrm{Mg}$ interage com o fator $\mathrm{B}$ formando $\mathrm{C} 3\left(\mathrm{H}_{2} \mathrm{O}\right) \mathrm{B}$, sobre o qual atua o fator $\mathrm{D}$ para formar $\mathrm{C} 3\left(\mathrm{H}_{2} \mathrm{O}\right) \mathrm{Bb}$, complexo chamado de C3-convertase de iniciação. Esta enzima, por sua vez, cliva novas moléculas de $\mathrm{C} 3 \mathrm{em}$ C3a e C3b. A ligação tioéster das moléculas de C3b sofre hidrólise, depositando-se sobre aceptores da superfície celular das partículas ditas ativadoras da via alternativa, como células infectadas por vírus, células tumorais, bactérias gram-negativas, fungos, protozoários $^{28}$.

$\mathrm{Na}$ presença de íons $\mathrm{Mg}, \mathrm{C} 3 \mathrm{~b}$ pode também se ligar ao fator $\mathrm{B}$ para formar C3bB. O fator $D$ que circula como enzima ativa e não é consumido na reação, atua então na porção $B$ da molécula para formar C3bBb, molécula lábil, sendo porém estabilizada pela agregação de uma molécula de properdina (P). A enzima C3bBbP resultante é denominada de C3-convertase de amplificação da via alternativa, clivando a seguir novas moléculas de C3 em C3a e C3b, sendo que este último pode ingressar na chamada "alça de amplificação", oferecendo mais C3b para a fase inicial desta via, ou se ligar ao complexo molecular C3bBb para formar $\mathrm{C} 3 \mathrm{bBb}(\mathrm{C} 3 \mathrm{~b})$, denominada de $\mathrm{C} 5$ convertase da via alternativa que, assim como C4b2a3b da via clássica, cliva C5 em C5a e C5b. Esta última molécula inicia a formação do CLM (C5b6789)28,34.

\section{- Complexo Lítico de Membrana}

O CLM é formado após a ativação de $\mathrm{C} 5, \mathrm{C6}, \mathrm{C7}, \mathrm{C8}$ e C9.

\section{Componente $\mathrm{C} 5$}

É uma betaglobulina com p.m. de 190 $\mathrm{kD}$, similar a C3 e C4, mas não contendo a ligação tioéster. A clivagem de C5 pela C5convertase, tanto da via clássica como alternativa, forma C5a e C5b. C5a é uma potente anafilatoxina, além de ser o mais importante fator quimiotático derivado do $\mathrm{SC}^{28}$.

\section{Componentes $\mathrm{Cb}$ e C7}

São beta-2-globulinas com características similares. Ambos estão compostos de cadeias simples, com p.m. aproximado de $125 \mathrm{kD}^{28}$.

\section{Componente C8}

É uma gama-I-globulina com p.m. de I 55 kD, composta de três cadeias alfa, beta e gama. A cadeia beta contém o sítio de interação com C5b6728.

\section{Componente C9}

É uma alfaglobulina constituída por uma cadeia simples, com p.m. de 79 kD28. Uma característica importante desta molécula é a sua capacidade de formar polímeros ${ }^{40}$, propriedade importante na formação do CLM ${ }^{4}$.

\section{Formação do Complexo Lítico de Membrana}

Uma vez formadas, as C5-convertases da via clássica ou alternativa atuam sobre as moléculas de C5 clivando-as em dois fragmentos, o menor C5a que se dissocia na fase fluída e o maior C5b. A formação de C5b marca o início da via efetora comum de ataque à membrana. $\mathrm{C} 5 b$, fracamente ligado a C3b, liga-se a C6 para formar o complexo C5b-6 e posteriormente a C7, formando o complexo C5b67, dissociando-se de C3b?.

O complexo C5b67 dispõe de um sítio de ligação meta-estável para membranas, fosfolipídios ou outras proteínas. Na ausên- cia de substratos apropriados, o complexo C5b67 sofre uma auto-agregação na fase fluída, perdendo sua potencial atividade citolítica. A ligação de C5b67 à membrana ocorre predominantemente através de interações hídricas e hidrofóbicas na superfície da membrana. Após a ligação de C8, a molécula de C9 é incorporada para formar o complexo C5b67899,42.

O complexo C5b678 tem a capacidade de causar a lesão de membranas celulares ${ }^{42}$. No entanto, para formar um complexo altamente citolítico, é necessário que várias moléculas de C9 liguem-se ao complexo C5b678 formando (C5b6789)n. Esta adição de C9 acelera o processo lítico consideravelmente. $O$ tamanho da lesão na membrana depende do número de moléculas de C9 ligadas ${ }^{43}$. A ligação de várias moléculas de C9 resulta da polimerização destas envolvendo pontes dissulfeto ${ }^{41}$.

O CLM insere-se na membrana alvo, levando a alterações na estrutura e função desta, ocorrendo a saída de material citoplasmático de baixo peso molecular, a entrada de líquido e sais, levando ao intumescimento celular e conseqüente rompimento das membranas por lise osmótica ${ }^{43,44}$.

O mecanismo exato da lise celular mediada pelo SC continua sendo objeto de discussões. Existem duas hipóteses a respeito. Uma teoria propõe que as superfícies polares dos últimos componentes do complemento formem conjuntamente um canal hidrofilico através da membrana, o chamado doughnut mode/45. O outro modelo propõe que as proteínas do complemento inseridas na membrana causariam uma distorção local da camada fosfolipídica da membrana, resultando nos chamados leaky patches $^{46}$.

As divergências entre ambas as teorias deu lugar a uma apaixonante discussão entre os defensores de cada uma delas ${ }^{47,48}$. Independente do mecanismo de ação, está demonstrado que o CLM causa a lesão de 
Tabela 2 - Proteínas solúveis que regulam a ativação do sistema complemento.

\begin{tabular}{|c|c|c|c|c|}
\hline Proteína & $\begin{array}{l}\text { PM } \\
\text { (KD) }\end{array}$ & $\begin{array}{l}\text { Concentração } \\
\text { sérica }(\mu \mathrm{g} / \mathrm{ml})\end{array}$ & $\begin{array}{l}\text { Interação } \\
\text { com: }\end{array}$ & Função \\
\hline $\begin{array}{l}\text { Esterase } \\
\text { inibidora de } \mathrm{Cl}\end{array}$ & 110 & 200 & $\mathrm{Clr}, \mathrm{Cls}$ & $\begin{array}{l}\text { Forma um complexo molecular } \\
\text { covalente com Clr e Cls, inibindo a atividade } \\
\text { destes. Liga-se a Cl inativo e previne a sua } \\
\text { ativação espontânea. }\end{array}$ \\
\hline $\begin{array}{l}\text { Proteína de } \\
\text { associação à } \\
\text { C4 (C4bp) }\end{array}$ & 500 & 250 & $C 4 b$ & $\begin{array}{l}\text { Liga-se a C4b, inibindo } \\
\text { competitivamente a ligação deste a } \\
\text { C2a. Atua como cofator do Fator I } \\
\text { na clivagem de C4b. Acelera a dissociação } \\
\text { de C3 convertase da via clássica. }\end{array}$ \\
\hline Fator $\mathrm{H}$ & 150 & 480 & $C 3 b$ & $\begin{array}{l}\text { Acelera a dissocoação de } \mathrm{C} 3 \\
\text { convertase da via alternativa } \\
(\mathrm{C} 3 \mathrm{bBb}) \text { por dissociação de } \mathrm{Bb} \text {. } \\
\text { Atua como cofator de Fator I na } \\
\text { clivagem de } \mathrm{C} 3 \mathrm{~b} \text {. Inibe competitivamente } \\
\text { a ligação do fator } \mathrm{Ba} \mathrm{C} 3 \mathrm{~b} \text {. }\end{array}$ \\
\hline Fator 1 & 88 & 35 & $C 4 b, C 3 b$ & $\begin{array}{l}\text { Cliva C4b e C3b, tendo C4bp, fator } \\
H, \text { CRI e PCM como cofatores. }\end{array}$ \\
\hline Inativador de & 310 & 35 & $\mathrm{C} 3 \mathrm{a}, \mathrm{C} 4 \mathrm{a}$ & $\begin{array}{l}\text { Inativa } \mathrm{C} 3 \mathrm{a}, \mathrm{C} 4 \mathrm{a} \text { e } \mathrm{C5} \text { a, clivando a } \\
\text { arginina-C terminal. }\end{array}$ \\
\hline $\begin{array}{l}\text { Proteína S } \\
\text { (vitronectina) }\end{array}$ & 83 & 505 & C5b-7 & $\begin{array}{l}\text { Liga-se ao complexo C5b-7 no seu } \\
\text { sítio de ligação à membrana, } \\
\text { prevenindo a inserção do CLM à membrana. }\end{array}$ \\
\hline $\begin{array}{l}\text { Sp } 40,40 \\
\text { Properdina }\end{array}$ & $\begin{array}{l}80 \\
220\end{array}$ & $\begin{array}{l}50 \\
20\end{array}$ & $\begin{array}{l}\text { C5b-9 } \\
\text { C } 3 b B b\end{array}$ & $\begin{array}{l}\text { Modula a formação de CLM. } \\
\text { Estabiliza a convertase da } \\
\text { alternativa. }\end{array}$ \\
\hline \multicolumn{5}{|c|}{$\begin{array}{l}\text { PM=peso molecular. } \mathrm{Kd}=\text { Kilodalton. } \mathrm{CLM}=\text { complexo lítico de membrana. } \mathrm{CRI}=\text { receptor de complemento tipo I. } \mathrm{PCM}=\text { proteína } \\
\text { cofatora de membrana. }\end{array}$} \\
\hline
\end{tabular}

vários tipos de membranas celulares ${ }^{38}$.

Existem proteínas, tanto no plasma sangüíneo como na membrana celular, que regulam e inibem a formação do CLM, protegendo principalmente células homólogas da ação lítica daquele ${ }^{9,47,49}$.

\section{Regulação da Ativação da Cascata do SC}

Uma ativação descontrolada do complemento pode levar à formação do CLM no próprio tecido e a uma formação excessiva de mediadores da inflamação. Isso normalmente não ocorre porque a ativação é regulada por várias proteínas plasmáticas e outras ligadas à membrana celular com funções específicas, mantendo um controle rigoroso da ativaçã $0^{50}$.
Além disso, as $\mathrm{C} 3$ e C5-convertases se dissociam rapidamente e C4b, C3b e C5b7 manifestam uma capacidade apenas transitória para a ligação à superfíciealvo. Então, o complemento de dada espécie é ineficiente para causar a lise de células autólogas. Graças a esses mecanismos de regulação existe um delicado equilíbrio entre a ativação e a inibição da cascata do SC, o que previne a lesão de células e tecidos próprios, mas permite a destruição efetiva de organismos estranhos $^{9,49}$. As tabelas 2 e 3 mostram algumas propriedades das proteínas reguladoras. Na tabela 4 estão citados os receptores de membrana para complemento e suas principais funções.

\section{Deficiências Genéticas ou Primárias}

As deficiências dos primeiros componentes da via clássica estão associadas a doenças por imunocomplexos ou autoimunes, como glomerulonefrites e lúpus eritematoso sistêmico (LES), respectivamente $^{5 !}$. Parece existir uma relação entre a produção de alguns elementos do SC (C4 e C2) e as proteínas produzidas pelo complexo principal de histocompatibilidade $(\mathrm{CPH}$, moléculas da classe I e II). Assim, o defeito genético na síntese dessas moléculas do SC também afetará o gene das proteínas do $\mathrm{CPH}$, levando a uma resposta imune anômala. A tabela 5 apresenta as condições patológicas associadas às deficiências de componentes do SC. 
Tabela 3 - Proteínas da membrana celular que regulam a ativação do sistema complemento.

\begin{tabular}{|c|c|c|c|c|}
\hline Proteína & PM(Kd) & Distribuição celular & Interação com & Função \\
\hline $\begin{array}{l}\text { Receptor de } \\
\text { complemento tipo I }\end{array}$ & $190-280$ & $\begin{array}{l}E, B, G, M, L \\
\text { Miócito* }\end{array}$ & C3b, C4b, iC3b & $\begin{array}{l}\text { Acelera a dissociação de C3 e C5 } \\
\text { convertase da via clássica e da via } \\
\text { alternativa. Atua com cofator do } \\
\text { Fator I na clivagem de C3b e C4b. } \\
\text { Promove a eliminação de } \\
\text { imunocomplexos em circulação. }\end{array}$ \\
\hline \multirow{4}{*}{$\begin{array}{l}\text { Proteína } \\
\text { cofatora de } \\
\text { membrana } \\
\text { (PCM) } \\
\text { Fator } \\
\text { acelerador da } \\
\text { dissociação } \\
\text { (DAF) } \\
\text { Fator de } \\
\text { restrição } \\
\text { homólogo } \\
\text { (HRF) } \\
\text { (C8bp) } \\
\text { Inibidor de } \\
\text { membrana de } \\
\text { lise reativa } \\
\text { (MIRL) } \\
\text { (CD59) } \\
\text { (protectina) }\end{array}$} & $45-70$ & $\begin{array}{l}\text { B,T,N,M, } \\
\text { Cels. } \\
\text { endoteliais, epiteliais, } \\
\text { fibroblastos e miócitos* }\end{array}$ & $C 3 b, C 4 b$ & $\begin{array}{l}\text { Atua como cofator do Fator I na } \\
\text { clivagem de C3b e C4b. }\end{array}$ \\
\hline & 70 & $\begin{array}{l}\text { E,L,P, } \\
\text { Miócito* }\end{array}$ & $\begin{array}{l}\text { C4b2a, } \\
\mathrm{C} 3 \mathrm{bBb}\end{array}$ & $\begin{array}{l}\text { Acelera a dissociação das C3 } \\
\text { convertases } \\
\text { Previne a associação de C3b com } \\
\text { fator B e C4b com C2. }\end{array}$ \\
\hline & 65 & $\begin{array}{l}\text { E,L,M,N,P } \\
\text { Miócito§ }\end{array}$ & $\mathrm{C} 8, \mathrm{C} 9$ & $\begin{array}{l}\text { Interfere na ligação de C8 e C9 } \\
\text { prevenindo a formação de CLM } \\
\text { em células homólogas. }\end{array}$ \\
\hline & $\begin{array}{l}18 \\
\text { Miócitoई }\end{array}$ & $E, L, M, N, P$ & $\begin{array}{l}\text { C7,C8 } \\
\text { complexo C5b-6. }\end{array}$ & Bloqueira a ligação de $\mathrm{C7}$ e C8 ao \\
\hline \multicolumn{5}{|c|}{$\begin{array}{l}\text { Kd=Kilodalton. } E=\text { eritrócitos. } B=\text { linfócitos } B . G=\text { granulócitos. } M=\text { monócitos. } L=\text { leucócitos. } T=\text { linfócitos } T . N=\text { neutrófilos. } \\
P=\text { plaquetas. } C L M=\text { complexo lítico de membrana. } \\
\text { *Fraca expressão. } \S \text { Forte expressão. }\end{array}$} \\
\hline
\end{tabular}

As deficiências dos primeiros componentes da via clássica não estão associadas a uma suscetibilidade aumentada para infecções, sugerindo que a via alternativa seja suficiente para a eliminação de agentes patogênicos. A deficiência genética mais comum é a de $\mathrm{C} 2$, embora tenham sido descritas deficiências de todos os componentes. Não obstante, a deficiência de C3 é a que leva a um maior comprometimento do SC, estando associada a infecções bacterianas piogênicas repetidas e de gravidade variável, podendo, inclusive, serem fatais².

Paradoxalmente, níveis circulantes diminuídos de $\mathrm{C} 3$ e de $\mathrm{C} 4$ podem representar um mecanismo protetor contra algumas doenças auto-imunes. A glomerulonefrite, por exemplo, é menos lesiva quando essas moléculas estão presentes em menor quantidade, especialmente C3, por haver menos deposição das mesmas nos glomérulos, levando a uma injúria quantitativamente menor $^{52}$

A deficiência de componentes da via clássica do SC está associada com o desenvolvimento de $L E S^{51,53}$. A apresentação da doença se inicia ainda na infância e adolescência nesses casos. Uma das alterações encontradas é a de uma proteína $\mathrm{Cl}$ q de baixo peso molecular, o que aumenta a possibilidade de que o turnover aumentado de $\mathrm{Cl}$ q na doença possa resultar na síntese errônea da cadeia da molécula. Ainda, a presença de anticorpos contra Clq está fortemente associada com LES severo, que afeta o rim, com vasculite urticariforme e com hipocomplementenemia ${ }^{54}$.

Indivíduos com deficiência de properdina, C3 ou elementos da via efetora do SC freqüentemente desenvolvem doença meningocócica ${ }^{55}$. A associação entre deficiência da via efetora e a infecção por Neisseria meningitidis é particularmente notável ${ }^{56}$. Tal suscetibilidade parece não ocorrer para outros agentes. A vacinação a cada três anos é recomendável para esses pacientes, embora os resultados ainda não sejam conclusivos $^{55}$. Contudo, a mortalidade por infecção meningocócica parece ser menor nesses pacientes do que em indivíduos imunocompetentes. A explicação possível é que 
Tabela 4 - Receptores de membrana para o sistema complemento.

\begin{tabular}{|c|c|c|c|c|}
\hline $\begin{array}{l}\text { Proteína } \\
\text { Receptor } \\
\text { tipo I } \\
\text { (CRI) }\end{array}$ & $\begin{array}{l}\text { Peso Molecular (kd) } \\
190-280\end{array}$ & $\begin{array}{c}\text { Interação específica com: } \\
\text { C } 3 b, C 4 b, i C 3 b\end{array}$ & $\begin{array}{c}\text { Distribuição celular } \\
\text { E, miócito }\end{array}$ & $\begin{array}{l}\text { Função } \\
\text { Promove a eliminação de } \\
\text { imunocomplexos da circulaccãa. } \\
\text { Acelera a dissociação de C3 e C5 } \\
\text { convertases de ambas as vias. Atua } \\
\text { como cofator do Fator I na clivaggem } \\
\text { de C3b e C4b. } \\
\text { Incrementa a fagocitose mediada } \\
\text { pelo receptor Fc. Intervém na } \\
\text { fagocitose independente do receptor } \\
\text { Fc. } \\
? \\
?\end{array}$ \\
\hline $\begin{array}{l}\text { Receptor } \\
\text { tipo } 2 \\
\text { (CR2) }\end{array}$ & 145 & $\begin{array}{l}\text { iC3b, } \\
\text { C3dg, C3d, } \\
\text { C3b, VEB }\end{array}$ & B & $\begin{array}{l}\text { Regulação das funções de linfócitos } \\
\text { B. Receptor para VEB. }\end{array}$ \\
\hline $\begin{array}{l}\text { Receptor } \\
\text { tipo } 4 \\
\text { (CR4) } \\
\text { Fc. }\end{array}$ & 260 & iC3b & $N, M, P$ & $\begin{array}{l}\text { Incrementa a fagocitose mediana } \\
\text { pelo receptor Fc. Intervém na } \\
\text { fagocitose independentemente do fator }\end{array}$ \\
\hline $\begin{array}{l}\text { Receptor } \\
\text { para } \\
\text { C3a/C3b }\end{array}$ & 100 & $\mathrm{C3a}, \mathrm{C4a}$ & $\begin{array}{l}\text { B } \\
\text { Mastócitos } \\
\text { Céls. endot., } \\
\text { N,M,m,P. }\end{array}$ & $\begin{array}{l}\text { Ligação de anafilatoxinas C3a, C4a. } \\
\text { Liberação de histamina e outros } \\
\text { mediadores da inflamação } \\
\text { Incremento na permeabilidade } \\
\text { celular } \\
\text { Promove a quimiotaxia. }\end{array}$ \\
\hline $\begin{array}{l}\text { Receptor } \\
\text { Clq }\end{array}$ & 65 & $\mathrm{Clq}$ & $\begin{array}{l}\text { B,M,P,m, } \\
\text { céls. endot. }\end{array}$ & $\begin{array}{l}\text { Intermedeia a ligação de } \\
\text { imunocomplexos à células } \\
\text { fagocitárias. }\end{array}$ \\
\hline
\end{tabular}

os pacientes com deficiência de C6 não são capazes de liberar agudamente a endotoxina do organismo invasor, evitando, assim, um dano tecidual mais abrangente ${ }^{56}$.

A deficiência de properdina da via alternativa aumenta a suscetibilidade à infecção por meningococo, que, neste caso, é fulminante e freqüentemente fatal. Esta deficiência tem herança ligada ao cromossomo $\mathrm{X}$, provocando meningococcemia fulminante em crianças do sexo masculino ${ }^{57}$.

Sabe-se que o CLM pode ser formado no sangue deficiente de $\mathrm{C}^{58}$. Essa molécula, entretanto, tem atividade hemolítica diminuída ou ausente.

\section{Deficiência Genética de Proteínas Reguladoras do SC}

Também foram descritas deficiências genéticas das proteínas reguladoras do SC. A deficiência do fator I leva a um consumo exagerado de $\mathrm{C} 3 b$, dos fatores $\mathrm{B}$ e $\mathrm{H}$ e de properdina, com conseqüente diminuição de C3 e aumento da suscetibilidade às infecções bacterianas do trato respiratório inferior, como otite, meningite ou septicemia ${ }^{59}$. Deficiências de fator acelerador da dissociação (DAF), fator de restrição homólogo (HRF) e CD59 nos eritrócitos são causa de hemoglobinúria paroxística noturna².

Pacientes com deficiência de $\mathrm{Cl}-\mathrm{INH}$ podem apresentar angioedema. $\mathrm{O}$ angioedema compreende um quadro de crises agudas ocasionais de edema nas extremidades, trato gastrointestinal e áreas orificiais. A orofaringe pode ser acometida, necessitando de intubação em alguns pacientes. $O$ defeito pode ser causado por síntese deficiente por defeito genético (angioedema hereditário), ou por catabolismo aumentado (angioedema adquirido). Pode ser secundário a drogas ou alergias alimentares ${ }^{60}$. Nos pacientes estudados por Cicardi et al. ${ }^{61}, 16$ entre 18 deles apresentavam auto-anticorpos que se ligavam ao $\mathrm{Cl}-\mathrm{INH}$, geralmente com baixa afinidade. 
Aproximadamente $85 \%$ dos pacientes têm angioedema do tipo I, na qual a estrutura da esterase inibidora de $\mathrm{Cl}(\mathrm{Cl}-\mathrm{INH})$ e sua função são normais, mas seus níveis plasmáticos estão reduzidos (5-30\% do normal). Os outros I $5 \%$ têm angioedema do tipo II, na qual a $\mathrm{Cl}-\mathrm{INH}$ é estrutural e funcionalmente anormal, embora permaneça com níveis séricos normais ou mesmo elevados. A ansiedade e/ou o trauma podem precipitar crises de edema nestes pacientes ${ }^{61}$.

O mecanismo de precipitação do edema ainda não está bem esclarecido. Acredita-se que qualquer evento que possa causar depleção local ainda maior de $\mathrm{Cl}-\mathrm{INH}$ no angioedema cause ativação de $\mathrm{Cl}$ na fase fluída. $\mathrm{O} \mathrm{Cl}$ ativado poderá, então, clivar C4 e C2. O fragmento de C2 é clivado posteriormente pela plasmina em um peptídeo vasoativo pequeno, a cinina-C2. Acredita-se que esta cinina seja responsável pela precipitação do edema no angioedema. A bradicinina também é uma candidata ${ }^{61}$.

\section{Deficiências Genéticas de Receptores do SC}

Ocorrem, também, deficiências de receptores. Os casos descritos são poucos; a deficiência de CR3 e CR4, por exemplo, origina alterações da adesão leucocitária2.

\section{Deficiências Adquiridas de Componentes do SC}

As deficiências adquiridas dizem respeito principalmente à síntese diminuída ou a um catabolismo aumentado ${ }^{62}$. O catabolismo acelerado está relacionado com LES e artrite reumatóide, mas é acompanhado por aumento compensatório de síntese.

$O$ angioedema adquirido é uma doença rara que pode se apresentar de duas formas. O tipo I está associado com outras doenças, mais comumente com doenças linfoproliferativas de células B. O tipo II é definido pela presença de um auto-anticor-

Tabela 5 - Doenças associadas com deficiências de componentes do sistema complemento.

\section{Proteína Deficiente}

Componentes da via clássica

Componentes da via efetora

Properdina

Deficiência de C8

Fator I

DAF, HRF, CD59

$\mathrm{Cl}-\mathrm{INH}$

CR3 e CR4

\section{Doenças Associadas}

Lúpus eritematoso sistêmico

Infecção meningocócica

Infecção meningocócica

Atividade hemolítica diminuída ou ausente

Aumento da suscetibilidade a infecções

bacterianas do trato respiratório inferior, otite, meningite e septicemia

Hemoglobinúria paroxística noturna

Edema angioneurótico tipos | e ||

Comprometimento do SNC

Alterações da adesão plaquetária

\section{SNC=sistema nervoso central. $\mathrm{Cl}-\mathrm{INH}$ : esterase inibidora de $\mathrm{Cl}$.}

po dirigido contra a molécula de $\mathrm{Cl}-\mathrm{INH}$. A diferenciação é muito importante, porque as intervenções terapêuticas são diferentes ${ }^{63}$.

Foi relatado um caso de deficiência adquirida de $\mathrm{Cl}$-INH em uma paciente como LES de 22 anos, em que houve comprometimento do sistema nervoso central. Os níveis de séricos de $\mathrm{C} 3$ eram normais, mas havia depleção de $\mathrm{C} 4, \mathrm{C} 2$, inibidor de $\mathrm{Cl}$ e de $\mathrm{Cl}$. Os pais da paciente, contudo, tinham níveis séricos normais. Os autores sugerem que a concentração extremamente reduzida de C4 possa ter levado ao comprometimento do $\mathrm{SNC}^{64}$.

A determinação do complemento sérico deve ser feita quando houver suspeita de algum defeito genético de um dos componentes ${ }^{2}$. No caso da glomerulonefrite difusa aguda, a complemento sérico serve como diagnóstico diferencial com outras patologias em que não há alteração dos níveis séricos do SC. Apesar de todos os componentes serem quantificáveis, habitualmente só a determinação do CH50 é utilizada.

\section{Conclusão}

O SC é uma cascata protéica com função importante na defesa humoral inespecífica. Para um funcionamento normal do mesmo, todos os componentes da cascata devem estar presentes em níveis plasmáticos normais e com uma função fisiológica adequada. A ativação do SC ocorre por duas vias, o que permite a resposta eficiente a diversos processos agressores. O dano provocado no tecido autólogo é controlado por mecanismos de regulação competentes.

As deficiências congênitas (primárias) ou adquiridas (secundárias) de proteínas de ativação da cascata do SC predispõem a doenças auto-imunes ou infecciosas específicas, em sua maioria por bactérias piogênicas de agressividade considerável, como, por exemplo, o meningococo. As deficiências de proteínas de regulação estão implicadas também em doenças do tipo autoimunes, como é o caso do angioedema e da hemoglobinúria paroxística noturna.

\section{ReFERÊNCIAS BIBLIOGRÁFICAS}

I. Pacheco SE, ShearerWT. Aspectos laboratoriais da imunologia. Clínicas Pediátricas da América do Norte 1994; 4: 655-87.

2. Hess C, Steiger JU, Schifferli JA. Complement and its role in immune response. Schweiz Med Wochenschr 1998; 128: 393-9.

3. Adelsberg B. A conceptual view of the complement system. Pediatric Annals 1987; 16 477-82.

4. Sunyer JO, Lambris JD. Evolution and diversity of the complement system of poikilothermic vertebrates. Immunol Rev 1998; 166: 39-57. 
5. Ruddy S. Plasma protein effectors of inflammation: Complement. In Kelley WN, Harris Jr. ED, Ruddy, S, Sledge CB, ed. Textbook of

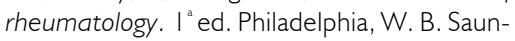
ders, 1981; 83-96.

6. Burger R. Complement biosynthesis. Factors of the alternative pathway. In Rother K; Till $\mathrm{GO}$, ed. The complement system. I ${ }^{\mathrm{a}}$ ed. Berlin, Springer-Verlag, 1988; 70-80.

7. Cole FS, Colten HR. Complement biosynthesis. Factors of the classical pathway. In Rother K, Till GO, ed. The complement system. I ${ }^{a}$ ed. Berlin, Springer-Verlag, 1988; 4470.

8. Morgan BP, Walport KBM. Complement deficiency and disease. Immunol Today 1991; 12: $301-6$.

9. Law SKA, Reid KBM. Complement. Oxford, Ilpress, $1988.72 \mathrm{p}$.

I0. Frank MM. Complement in the pathophysiology of human disease. N Eng J Med 1987; 316:1525-1550.

I I. Frank MM, Fries LF. The role of complement in inflammation and phagocytosis. Immunol Today 1991; 12: 322-6.

12. Bjork J, Hugli TE, Smedegard G. Microvascular effects of anaphylatoxins $\mathrm{C} 3 \mathrm{a}$ and $\mathrm{C} 5 \mathrm{a}$. J Immunol 1985; 134: III5-9.

13. Tagami $H$. The role of complement-derived mediators in inflammatory skin diseases. Arch Dermatol Res 1992; 284: S2-9.

14. Adler S, Baker PJ, Johnson RJ, Ochi RF, Pritzl P, Couser WG. Complement membrane attack complex stimulates production of reactive oxygen metabolites by cultured rat mesangial cells. J Clin Invest 1986; 77: 762-7.

15. Bürgi B, Brunner T, Dahiden CA. The degradation product of the $\mathrm{C} 5 \mathrm{a}$ anaphylatoxin C5adesarg retains basophil-activating properties. Eur J Immunol 1994; 24: I 583-9.

16. Ehrengruber UM, Geiser T, Deranleau DA. Activation of human neutrophils by $\mathrm{C} 3 \mathrm{a}$ and C5a. Comparison of the effects on shape changes, chemotaxis, secretion, and respiratory burst. FEBS Lett 1994; 346: 1 8 | -4.

17. Hartmann K, Henz BM, Krüger-Krasagakes $S$, Köhl J, Buerger R, Guhl S et al. C3a and C5a stimulate chemotaxis of human mast cells. Blood 1997; 89: 2863-70.

18. Haeney MR. The role of the complement cascade in sepsis. I Antimicrob Chemother 1998; 4 (Suppl A):4 I-6.

19. Frank MM. Complement: a brief review. J Allergy Clin Immunol 1989; 84:4I I-20.

20. Shen Y, Halperin JA, Benzaquen L, Lee CM. Characterization of neuronal cell death induced by complement activation. Brain Res Brain Res Protoc 1997; 1: 186-94.

21. Lachmann PJ. Microbial immunology: a new mechanism for immune subversion. Curr Biol 1998; 29 8:3 R99-RI01.

22. Kisselev AF, Mentele R, Helm KVD. Cleavage of the complement system C3 component by HIVI proteinase. Biol Chem 1997; 378: 439-42.

23. Lubinski J, Nagashunmugam T, Friedman HM. Viral interference with antibody and complement. Semin Cell Dev Biol 1998; 9:329-37.
24. Seya T, Nomura M, Murakami Y, Begum NA, Matsumoto M. Nagasawa S. CD46 (membrane cofactor protein of complement, measles virus receptor): structural and functional divergence among species (review). Int J Mol Med 1998; 1: 809-16.

25. Ziccardi RJ. Nature of the metal ion requirement for assembly and function of the first component of human complement. J Biol Chem 1983; 258:6187-92.

26. Lim HW. The complement system. Activation, modulation, and clinical relevance. Dermatol Clin 1990; 8: 609-I8.

27. Winkelstein JA. Complement and natural immunity. Clin Immunol Allergy 1985; 3: 42139.

28. Silva WD, Kipnis TL. Sistema complemento: um engenhoso mecanismo bioquímico, um co-participante na defesa natural e um mediador de interações celulares. Rev Ass Med Brasil 1984; 30: 67-72.

29. Loos M. Classical pathway of activation. In Rother K, Till GO ed. The complement system. I ${ }^{\text {a }}$ ed. Berlin, Springer-Verlag, 1988; 13654.

30. Kerr MA. The human complement system: assembly of the classical pathway $\mathrm{C} 3$ convertase. Biochem J 1980; 189: 173-81.

31. Polley MJ, Müller-Eberhard HJ. The second component of the human complement: Its isolation, fragmentation by $\mathrm{Cl}$ esterase, and incorporation into C3 convertase. J Exp Med 1968; 128: 533-5।.

32. Bhakdi S, Tranum-Jensen J. Membrane damage by complement. Biochim Biophys Acta 1983; 737: 343-72.

33. Pillemer L, Blum L, Lepow IH, Ross DA, Todd EW, Wardlaw AC. The properdin system and immunity: I. Demonstration and isolation of a new serum protein, properdin, and its role in immune phenomena. Science 1954; 120: 279-51.

34. Williams LW, Burks AW, Steele RW. Complement: function and clinical relevance. Ann Allergy 1988; 60: 293-301.

35. Rother K, Till GO. Phases of Complement Research and Nomenclature. In Rother K, Till $\mathrm{GO}$ ed. The complement system. I ed. Berlin, Springer-Verlag, 1988; I-4.

36. Götze $O$. The alternative pathway of activation In: Rother K, Till GO ed. The complement system. I' ed. Berlin, Springer-Verlag, 1988; 154-67.

37. Platts-Mills TAE, Ishizaka K. Activation of the alternative pathway of human complement by rabbit cells. J Immunol 1974; I I3: 348-58.

38. Klaus GGB. Role of complement in the induction of antibody responses. In Rother K, Till GO ed. The complement system. I $^{a}$ ed. Berlin, Springer-Verlag, 1988; 327-37.

39. Glicas PC, Pinckard RN, Olson MS. In vitro activation of complement by isolated human heart subcellular membranes. I Immunol 1979; |22: |46-5।.

40. Podack ER, Tschopp J. Polymerization of the ninth component of complement (C9): Formation of poly (C9) with a tubular ultras- tructure resembling the membrane attack complex of complement. Proc Natl Acad Sci USA 1982; 79: 574-78.

4I. Yamamoto K, Migita S. Mechanisms for the spontaneous formation of covalently linked polymers of the terminal membranolytic complement protein (C9). J Biol Chem 1983; 258 : 7887-9.

42. Biesecker G. Membrane attack complex of complement as a pathologic mediator. Lab Invest 1983; 49: 237-249.

43. Hansch GM. The complement attack phase. In Rother K, Till GO ed. The complement system. I ${ }^{2}$ ed. Berlin, Springer-Verlag, 1988; 202 30.

44. Morgan BP. Regulation of the complement membrane attack pathway. Crit Rev Immuno 1999; 19: 173-98.

45. Mayer MM. Mechanism of cytolysis by complement. Proc Natl Acad Sci USA 1972; 69: 2954-8.

46. Esser AF, Kolb WP, Podack ER, Muller-Eberhard HJ. Molecular reorganization of lipid bilayers by complement: a possible mechanism for membranolysis. Proc Natl Acad Sci USA 1979; 76: p. 1410-4.

47. Bhakdi S, Tranum-Jensen J. Complement lysis: a hole is a hole. Immunol Today 1991; 9: 318-20.

48. Esser AF. Big MAC attack: complement proteins cause leaky patches. Immunol Today 1991; 12: 316-8

49. Lachmann PJ. The control of homologous lysis. Immunol Today 1991; 12: 312-5.

50. Meri S, Jarva H. Complement regulation. Vox Sang 1998; 74: (Suppl 2) 291-302.

5I. Sullivan KE. Complement deficiency and autoimmunity. Curr Opin Pediatr 1998 Dec 10:6 600-6.

52. Sheerin NS, Springall T, Carroll MC, Hartley B, Sacks $\mathrm{SH}$. Protection against anti-glomerular basement membrane (GBM)-mediated nephritis in C3- and C4-deficient mice. Clin Exp Immunol 1997; I I0: 403-9.

53. Christiansen FT, Zhang WJ, Griffiths M, Mallal AS, Dawkins RL. Major histocompatibility complex complement deficiency, ancestral haplotypes and systemic lupus erythematosus: C4 deficiency explains some but not all of the influence of the MHC. J Rheumatol 1992; 9 ; 1350-8.

54. Walport MJ, Davies KA, Botto M. Clq and systemic lupus erythematosus. Immunobiology 1998; 199: 265-85.

55. Fijen CA, Kuijper EJ, Drogari-Apiranthitou M, Van Leeuwen Y, Daha MR, Dankert J. Protection against meningococcal serogroup ACYW disease in complement-deficient individuals vaccinated with the tetravalent meningococca capsular polysaccharide vaccine. Clin Exp Immunol 1998; 114: 362-9.

56. Lehner PJ, Davies KA, Walport MJ et al. Meningococcal septicaemia in a C6-deficient patient and effects of plasma transfusion on lipopolysacharide release. Lancet 1992; 340: | 379-8 |

57. Sjoholm AG, Kuijper EJ, Tijssen CC, et al. Dysfunctional properdin in a Dutch family with meningococcal disease. N Eng J Med 1988 319: 33-7. 
58. Hogasen K, Mollnes TE, Nürnberger W, Pausa M, Fukumori Y, Tedesco F. Characterization of soluble terminal complement complex assembled in C8 beta-deficient plasma and serum. Scand J Immunol 1998; 48: 26I-8.

59. Leitão MF, Vilela MM, Rutz R, Grumach AS, Condino-Neto A, Kirschfink M. Complement factor I deficiency in a family with recurrent infections. Immunopharmacology 1997; 38: 207-13.

60. Wagner WO. Angioedema: frightening and frustrating. Cleve Clin J Med 1999; 66: 203-5.

61. Cicardi M, Bergamaschini L, Cugno M, Beretta A, Zingale LC, Colombo M, Agostoni A. Pathogenetic and clinical aspects of $\mathrm{Cl}$ inhibitor deficiency. Immunobiology 1998; 199: 366-76.

62. Sakamoto M, Fujisawa Y, Nishioka K. Physiologic role of the complement system in host defense, disease, and malnutrition. Nutrition | 998; |4: 39|-8.

63. Heymann WR. Acquired angioedema. J Am Acad Dermatol 1997; 36: 61 I-5.
64. Nakamura S, Yoshinari M, Saku Y, Hirakawa K, Miishima SC, Murai Ket al. Acquired Cl inhibitor deficiency associated with systemic lupus erythematosus affecting the central nervous system. Ann Rheum Dis 1992; 50: 713-6.

Artigo recebido: 28/07/1999 Aceito para publicação: 03/04/2000

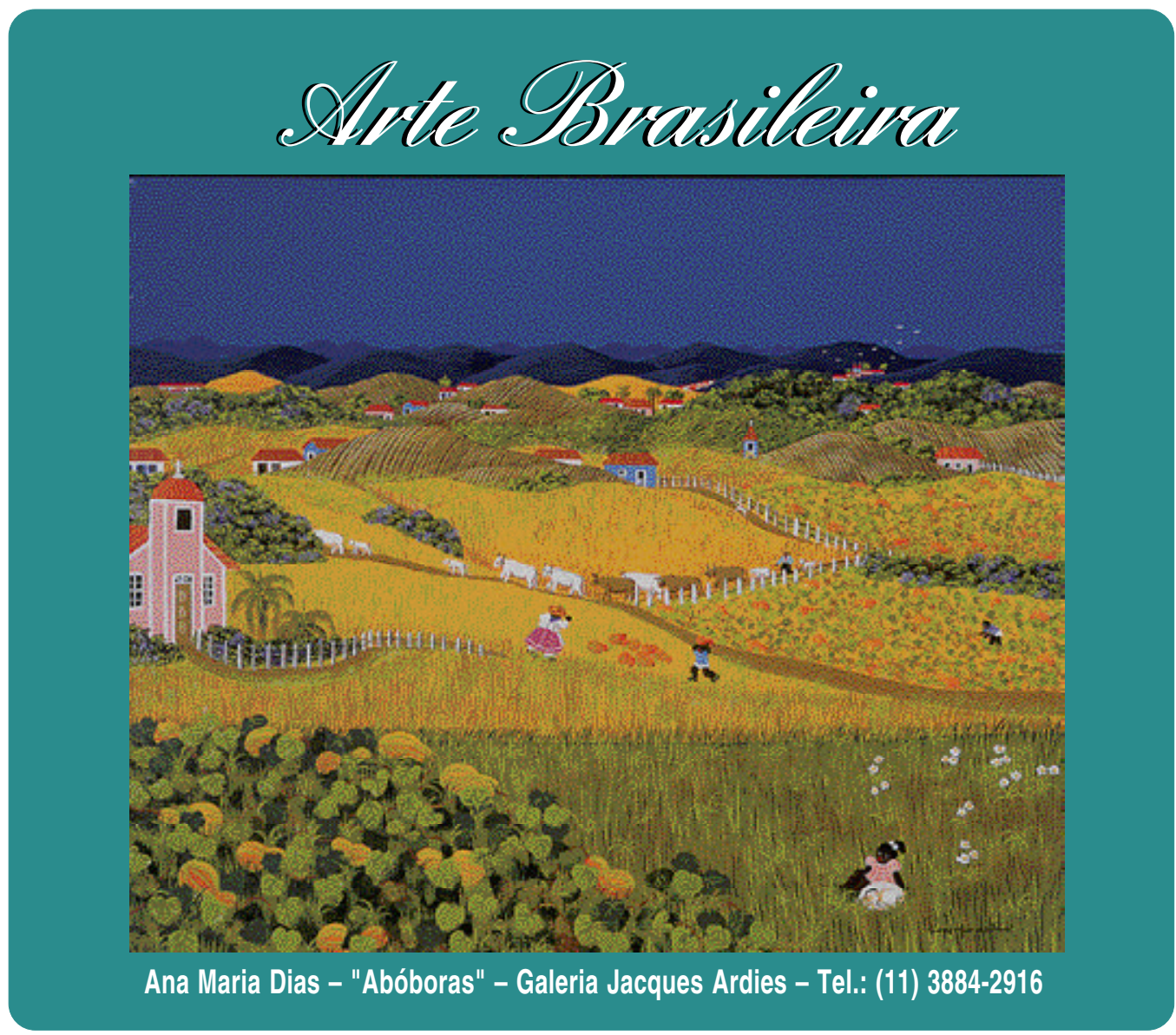

